\title{
Blood Glucose Monitoring and Sharing Amongst People With Diabetes and Their Facilitators: Cross-sectional Study of Methods and Practices
}

Amr Jamal $^{1 *}$, MD; Shabana Tharkar ${ }^{2 *}$, BDS, MSc; Weam Saleh Babaier ${ }^{3}$, MBBS; Shrooq Faisal Alsomali ${ }^{3}$, MBBS; Allulu Saad Alsulayhim ${ }^{3}$, MBBS; Monera Abdulkareem Alayuni ${ }^{3}$, MBBS; Nada Abdulaziz Aldakheel ${ }^{3}$, MBBS; Safa Sultan Al-Osaimi ${ }^{3}$, MBBS; Norah Alshehri ${ }^{4}$, MBBS, MD; Mohammed Batais ${ }^{4}$, MBBS, MD

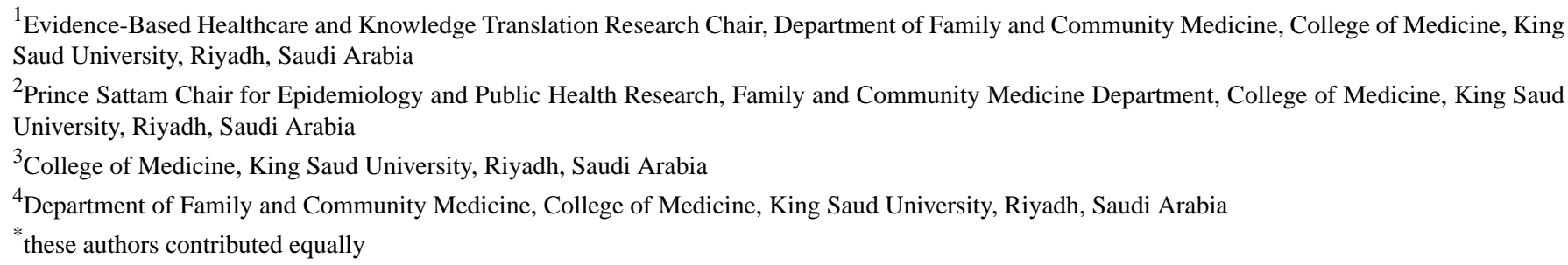

Corresponding Author:

Amr Jamal, MD

Evidence-Based Healthcare and Knowledge Translation Research Chair

Department of Family and Community Medicine, College of Medicine

King Saud University

90714 Khalid bin Walied Road

Riyadh, 12372

Saudi Arabia

Phone: 9664690822

Email: amrjamal@ksu.edu.sa

\begin{abstract}
Background: The last two decades have witnessed a burgeoning rise in the prevalence of diabetes globally. It has already reached epidemic proportions in Saudi Arabia, with reported high risk among women. As a result, diabetes monitoring and self-management programs are being highly prioritized for diabetes control and management.

Objective: To investigate measuring and sharing practices of the self-monitoring of blood glucose (SMBG) among patients with type 1 or 2 diabetes using insulin.

Methods: A cross-sectional study was conducted on a sample of 203 patients attending primary care clinics at a tertiary care center. The questionnaire assessed the measuring, recording, and sharing of SMBG practices of patients having diabetes with their physicians. The methods used for recording and sharing were categorized into paper-based and electronic-based. In addition, the determinants of the different methods used and frequency of sharing were analyzed.

Results: The overall monitoring prevalence was 95\% (193/203), and 57\% (117/203) of participants shared the SMBG results. Among the 193 individuals that performed self-monitoring, 138 (72\%) performed daily monitoring, and 147 (76\%) recorded their blood sugar levels. Almost 55\% (81/147) used paper-based materials like notebooks and paper for recording, while the rest $(66 / 147,45 \%)$ used digital devices like laptops and smartphones. A shift towards the use of digital devices and smart applications was observed in patients below 50 years of age. The digitally recorded blood glucose measurements were being shared thrice more often than the recordings made on paper or in notebooks (OR [odds ratio] 2.8; $P=.01$ ). Patients $>50$ years of age (OR 2.3; $P=.02$ ), with lesser formal education, married (OR 4.2; $P<.001$ ), with smaller family size (OR $2.6 ; P=.01$ ), having type 2 diabetes (OR $4.1 ; P<.001)$ and any comorbid conditions $(\mathrm{OR} 2.6 ; P=.01)$ were associated with higher odds of using paper-based sharing methods. Only the female gender and type 2 diabetes were associated with increased frequency of sharing, while uncontrolled diabetes, the presence of other comorbidities, and duration of diabetes did not show any influence.
\end{abstract}


Conclusions: Good monitoring and optimal sharing practices were found. Sharing using electronic devices can be emphasized. Diabetes self-management programs can incorporate the use of digital technology in training sessions. Digital literacy and its applications in health care may enhance SMBG practices resulting in better diabetes control.

(JMIR Diabetes 2021;6(4):e29178) doi: 10.2196/29178

\section{KEYWORDS}

blood glucose monitoring; diabetes self- management; insulin users; Saudi Arabia

\section{Introduction}

Optimal glycemic control is central to the management of both type 1 and type 2 diabetes. Poor glycemic control has been causally associated with microvascular and macrovascular complications. Hence it is imperative to target and maintain optimum diabetes control [1-3]. Regular monitoring of blood glucose levels is an integral part of diabetes management [4]. Clinical monitoring of glycated hemoglobin levels $\left(\mathrm{HbA}_{1 \mathrm{c}}\right)$ that determine the 3-month average blood glucose status and daily home monitoring of the capillary blood glucose levels called self-monitoring of blood glucose (SMBG) are the two principal methods of monitoring blood glucose levels [5]. According to the 2012 American Diabetes Association (ADA) guidelines, SMBG is recommended at least thrice daily for those on multiple insulin therapy and a minimum once daily for noninsulin users [6]. Diabetes management reached a significant milestone with the introduction of glucometer-based SMBG. Short-term benefits of regular monitoring of glucose levels include hypoglycemia prevention and the proven benefit to the physicians in adjusting the insulin doses. Scientific evidence suggests there is a substantial reduction in diabetes-related complications due to the long-term benefits of regular blood glucose monitoring [7-10].

Furthermore, in addition to monitoring, the practice of sharing blood glucose levels with the physicians is highly recommended by the consensus of organizations such as the ADA, International Diabetes Federation, and European Association for the Study of Diabetes in the holistic management of hyperglycemia [11-13]. However, the frequency of monitoring can be individualized according to the patient's glycemic status, presence of other comorbidities and diabetes-related complications, lifestyle, and type of drugs administered [14]. Regular monitoring and sharing have been associated with significant predictors like motivation from the physician and family, fear of hypoglycemia, and the desire for good glycemic control [15]. Sharing SMBG results, in addition to $\mathrm{HbA}_{1 \mathrm{c}}$, has been the basis for drug dosing and physicians' decision-making $[14,15]$. The frequency of SMBG monitoring and sharing influence the progressive monitoring behavior that ultimately has a profound impact on glycemic control. Technological advancements in monitoring devices have simplified the process of monitoring and sharing. Digital devices like smartphones, with specific health apps installations and glucometers linked to smart devices, offer a conducive medium for effortless and error-free sharing of measurements.

Scientific literature reporting SMBG practices among insulin users is often sparse in Saudi Arabia. Our study investigated the frequency of blood glucose monitoring and the methods adopted to measure, record, and share SMBG results by patients with diabetes and on treatment with insulin. We hypothesized that at least $50 \%$ shared the results with their physicians, and $50 \%$ of the patients used paper-based methods for recording and sharing. The associated factors that determine the sharing practices were also investigated. Additionally, the physicians' advice on results-sharing and their perceptions on the adequacy of SMBG results in adjusting insulin dose was also determined. The results would provide a comprehensive understanding of the prevailing patient practices related to SMBG that may identify determinants of good monitoring and sharing practices. Moreover, the findings may suggest the improvement of diabetes education programs by adopting changing trends in digital technology use and facilitating patient empowerment in optimum diabetes management.

\section{Methods}

\section{Study Design}

A cross-sectional study design was incorporated to investigate the measurement of SMBG among patients with diabetes using insulin. The study was conducted from November 2019 until April 2020. Patients with a known diabetes diagnosis and on insulin treatment formed the primary sampling unit. The patients were identified from the appointment list on the hospital's electronic health records at the primary care clinics, family medicine clinics, and specialized diabetes care centers of the university hospital. During the first 4 months of the study period, data was collected at the clinics, transitioning to telephone surveys during COVID-19 restrictions during March and April 2020. A well-trained team was involved in the data collection. Patients with cognitive impairment, pregnant women, and those requiring hospitalization were excluded. The selected patients' physicians were also interviewed to assess the advice and use of shared $\mathrm{SMBG}$ results.

\section{Blood Glucose Measurements of Patients}

Every patient with diabetes is usually provided with a glucose self-monitoring kit, including a diary, to maintain the self-management plan provided by the university hospital at the time of the first diagnosis or during the first follow-up visit. The patients record the SMBG results according to their preference and convenience using the given diaries or digital devices. Paper-based methods consisted of blood glucose readings measured and shared via diaries, notebooks, or paper, while smartphones, laptops, and glucometers were categorized as digital or electronic methods. 


\section{Study Questionnaire and Sample Size}

The questionnaire was comprised of two parts. The first section included questions regarding patient demographics, history of diabetes, and SMBG practices that were administered to the patients. The second part of the questionnaire included 4 questions were addressed to the patient's attending physician, relating to the physician's advice on sharing SMBG results and the use of results in adjusting the patient's insulin dose. In addition, a pilot test was conducted on 20 subjects (excluded from the sample) attending primary care clinics to estimate the interview time, ensure comprehensibility, and test logistics. A sample size of 203 was obtained using the formula for a single proportion $\mathrm{N}=\mathrm{z}^{2} \times \mathrm{P} \times(1-\mathrm{P}) / \delta 2$, where $P=75 \%$, the proportion that shared the SMBG results during the pilot test, $\mathrm{z}=90 \% \mathrm{CI}$, and $P=.05$.

\section{Ethical Considerations}

A consent form was attached to the questionnaire explaining the research purpose, research benefits, a statement of confidentiality, and a guarantee of participants' right to drop out of the study at any stage. Participating in this study was nonobligatory, and no rewards were given to participants upon completing the questionnaire. Study approval was obtained by the department's ethics committee (reference number CMED 305-F 14-2018-19).

\section{Data Analysis}

Descriptive statistics such as mean and standard deviation were derived for continuous variables. Frequency and percentage were computed for binary and categorical data. Bivariate statistical analysis was carried out using appropriate statistical tests based on the type of study and outcome variables. Pearson's chi-square test was used to test the differences in observed frequencies between the two groups, paper-based and electronic-based, considering the different categorical variables in $2 \times 2$ table. A $P$ value of $<.05$ was used to report the statistical significance. The odds ratio (OR) and upper and lower $95 \% \mathrm{CI}$ were taken from the risk estimate.

\section{Results}

The final sample included 203 participants. The mean age of the study participants was 51.8 years (SD 16.6). Type 2 diabetes was predominant $(155 / 203,76 \%)$. The mean $\mathrm{HbA}_{1 \mathrm{c}}$ was $9.5 \%$, and the majority $(193 / 203,95 \%)$ of the participants showed poor glycemic control $\left(\mathrm{HbA}_{1 \mathrm{c}}>7 \%\right)$. Table 1 illustrates the demographic characteristics of the study participants. Chronic diseases were reported in more than half $(119 / 203,58.6 \%)$ of the study participants. The most prevalent comorbidity was hypertension $(90 / 203,44.3 \%)$, followed by dyslipidemia $(42 / 203,20.7 \%)$. Other commonly reported comorbidities were thyroid disorders, mainly hypothyroidism, with asthma and kidney diseases accounting for 20\% (40/203).

Table 2 displays the frequency of measuring, recording, and sharing of the SMBG results. A majority of participants (193/203, 95\%) reported measuring their blood glucose levels. Almost 81\% (156/197) measured themselves, and 19\% (37/197) sought family assistance. Of the 193 individuals, 147 (76\%) recorded the measurements, and among those who recorded, $117(79 \%)$ shared the readings with their physicians. More than half of the participants $(65 / 117,55.6 \%)$ preferred paper-based methods like notebooks and paper sheets, while the rest (52/117, $44.4 \%$ ) used digital devices like glucometers, mobile phones, laptops, and smartphone apps to share SMBG results. Significance testing with increased frequency of sharing showed only female participants and patients with type 2 diabetes were significantly associated with increased sharing (data not shown). 
Table 1. Sociodemographic and clinical characteristics of patients with diabetes on insulin therapy.

\begin{tabular}{|c|c|}
\hline Variable & Frequency $(\mathrm{N}=203)$ \\
\hline \multicolumn{2}{|l|}{ Age (in years), $n(\%)$} \\
\hline$\leq 50$ & $87(42.9$ \\
\hline$>50$ & $116(57.1)$ \\
\hline \multicolumn{2}{|l|}{ Gender, n (\%) } \\
\hline Female & $109(53.7)$ \\
\hline Male & $94(46.3)$ \\
\hline \multicolumn{2}{|l|}{ Nationality, n (\%) } \\
\hline Saudi & $193(95.1)$ \\
\hline Non-Saudi & $10(4.9)$ \\
\hline \multicolumn{2}{|l|}{ Education, $\mathbf{n}(\%)$} \\
\hline School education & $137(67.5)$ \\
\hline Advanced education & $66(32.5)$ \\
\hline \multicolumn{2}{|l|}{ Employment status, n (\%) } \\
\hline Employed & $55(27.1)$ \\
\hline Retired & $48(23.6)$ \\
\hline Not employed & $100(49.3)$ \\
\hline \multicolumn{2}{|l|}{ Marital status, n (\%) } \\
\hline Married & $150(73.9)$ \\
\hline Not married & $53(26.1)$ \\
\hline \multicolumn{2}{|c|}{ Monthly family income, n (\%) } \\
\hline USD $<2666$ & $122(60.1)$ \\
\hline USD > 2667 & $81(39.9)$ \\
\hline \multicolumn{2}{|l|}{ Family members, $\mathbf{n}(\%)$} \\
\hline$\leq 6$ & $103(50.7)$ \\
\hline$>6$ & $100(49.3)$ \\
\hline \multicolumn{2}{|l|}{ Type of diabetes, n (\%) } \\
\hline Type 2 & $155(76.4)$ \\
\hline Type 1 & $48(23.6)$ \\
\hline \multicolumn{2}{|c|}{ Duration of diabetes (years), n (\%) } \\
\hline$\leq 10$ & $73(36)$ \\
\hline$>10$ & $130(64)$ \\
\hline \multicolumn{2}{|l|}{$\mathrm{HbA}_{1 c^{a}}, \mathbf{n}(\%)$} \\
\hline Uncontrolled (>7.0\%) & $193(95.1)$ \\
\hline Controlled & $10(4.9)$ \\
\hline \multicolumn{2}{|l|}{ Other chronic diseases } \\
\hline Yes & $119(58.6)$ \\
\hline No & $84(41.4)$ \\
\hline $\mathrm{HbA}_{1 \mathrm{c}}$, mean $(\mathrm{SD})$ & $9.5(1.8)$ \\
\hline
\end{tabular}

${ }^{\mathrm{a}} \mathrm{HbA}_{1 \mathrm{c}}$ : glycated hemoglobin levels. 
Table 2. Frequency of self-monitoring of blood glucose practices.

\begin{tabular}{ll}
\hline Variables & Frequency $(\mathrm{N}=203)$ \\
\hline Measuring, $\mathrm{n}(\%)$ & $193(95.1)$ \\
Recording $(\mathrm{n}=193), \mathrm{n}(\%)$ & $147(76.2)$ \\
Sharing $(\mathrm{n}=147), \mathrm{n}(\%)$ & $117(79.6)$ \\
\# of times shared (n=117), $\mathbf{n}(\boldsymbol{\%})$ & \\
$\quad$ Daily & $25(21.4)$ \\
Week & $17(14.5)$ \\
Monthly & $36(30.8)$ \\
Every 3 months & $39(33.3)$ \\
Methods of sharing (n=117), $(\%)$ & \\
Notebook for recording blood glucose results & $49(41.9)$ \\
Paper & $16(13.7)$ \\
Glucometer & $15(12.8)$ \\
Laptop or Smartphone & $20(17.1)$ \\
Smart Applications & $17(14.5)$ \\
\hline
\end{tabular}

Table 3 illustrates the determinants of the methods used for sharing. Patients aged $>50$ years were twice as likely to use paper-based methods (OR 2.3; $P=.02$ ) for recording and sharing the measurements. Being married increased the odds of using paper-based methods for sharing SMBG results by 4 times (OR $4.2 ; P<.001$ ). Small family sizes (less than 6 family members) were also associated with the increased use of the paper-based methods $(\mathrm{OR}=2.6 ; P=.01)$. In addition, type 2 diabetes and the presence of any chronic ailment were associated with a greater likelihood of using paper methods. Although not reaching the level of statistical significance, those attaining formal education were twice as likely to rely on paper-based methods for recording and sharing the results with their physicians.
Furthermore, digitally recorded blood glucose results were shared almost three times more frequently than those recorded on paper or notebooks (OR 2.8; $P=.01$ ). Other characteristics such as gender and $\mathrm{HbA}_{1 \mathrm{c}}$ were not significantly correlated with the methods of sharing.

Additionally, physicians' role in patients' SMBG practices was also analyzed. Most of the patients' physicians (196/203, 96.6\%) encouraged them to monitor their blood glucose levels regularly. In addition, almost $97.4 \%$ (114/117) of the physicians checked the SMBG results before adjusting the insulin dose. On the other hand, $60 \%(112 / 203)$ of the physicians perceived that SMBG measurements were adequate to adjust the patients' insulin dose. 
Table 3. Determinants of paper-based and electronic methods of sharing.

\begin{tabular}{|c|c|c|c|c|c|c|}
\hline Variable & Paper-based sharing, $\mathrm{n}$ & Electronic-based sharing, $\mathrm{n}$ & $\chi^{2}$ value & $P$ value & OR & $95 \% \mathrm{CI}$ \\
\hline Age (years) & & & 4.86 & $.02^{\mathrm{a}}$ & 2.3 & $1.1-4.8$ \\
\hline$>50$ & 42 & 23 & & & & \\
\hline$\leq 50$ & 23 & 29 & & & & \\
\hline Gender & & & 1.17 & .27 & 0.6 & $0.3-1.3$ \\
\hline Male & 26 & 26 & & & & \\
\hline Female & 39 & 26 & & & & \\
\hline Education & & & 3.47 & .06 & 2.0 & $0.9-4.4$ \\
\hline School education & 47 & 29 & & & & \\
\hline Advanced education & 18 & 23 & & & & \\
\hline Employment status & & & 0.00 & .97 & 0.9 & $0.4-2.3$ \\
\hline Not employed & 32 & 27 & & & & \\
\hline Employed & 18 & 15 & & & & \\
\hline Marital status & & & 11.77 & $<.001$ & 4.2 & $1.8-9.8$ \\
\hline Married & 54 & 28 & & & & \\
\hline Not married & 11 & 24 & & & & \\
\hline Monthly family income (Saudi Riyal) & & & 0.17 & .67 & 1.1 & $0.5-2.4$ \\
\hline USD $<2666$ & 40 & 30 & & & & \\
\hline USD $>2667$ & 25 & 22 & & & & \\
\hline Family members & & & 6.36 & .01 & 2.6 & $1.2-5.5$ \\
\hline$\leq 6$ & 39 & 19 & & & & \\
\hline$>6$ & 26 & 33 & & & & \\
\hline Type of diabetes & & & 9.55 & $<.002$ & 4.1 & $1.6-10.4$ \\
\hline Type 2 & 57 & 33 & & & & \\
\hline Type 1 & 8 & 19 & & & & \\
\hline Duration of diabetes (years) & & & 0.27 & .59 & 1.2 & $0.5-2.6$ \\
\hline$\leq 10$ & 23 & 16 & & & & \\
\hline$>10$ & 42 & 36 & & & & \\
\hline $\mathrm{HbA}_{1 \mathrm{c}}{ }^{\mathrm{b}}$ & & & $-{ }^{c}$ & .23 & 0.2 & $0.1-1.6$ \\
\hline Controlled $(<7)$ & 2 & 5 & & & & \\
\hline Uncontrolled & 63 & 47 & & & & \\
\hline Other chronic diseases & & & 6.12 & .01 & 2.6 & $1.2-5.6$ \\
\hline Yes & 47 & 26 & & & & \\
\hline No & 18 & 26 & & & & \\
\hline Times they share & & & 6.24 & .01 & 2.8 & $1.2-6.4$ \\
\hline$>1$ Month & 28 & 11 & & & & \\
\hline$\leq 1$ Month & 37 & 41 & & & & \\
\hline
\end{tabular}

${ }^{\mathrm{a}} P$ values in italic indicate differences between variables are statistically significant.

${ }^{\mathrm{b}} \mathrm{HbA}_{1 \mathrm{c}}$ : glycated hemoglobin levels.

${ }^{\mathrm{c}}$ Cell count less than 5 did not give the chi-square constant. 


\section{Discussion}

\section{Principal Findings}

The measuring, recording, and sharing of SMBG practices in patients with diabetes using insulin were investigated. Some of the major findings of this study show that $95 \%$ (193/203 of the total study population monitored their blood glucose at any given time, and 72\% (138/193) performed daily monitoring. Among those who monitored, close to $76 \%$ (147/193) recorded the measurements, of which $79 \%(117 / 147)$ shared it with their physicians. But the overall prevalence of sharing in the total sample was $57.6 \%(117 / 203)$ only. The majority of the participants $(81 / 147,55 \%)$ used notebooks or paper for recording SMGB readings, although smart applications were also frequently used. Being $>50$ years of age, with lesser formal education, married, with smaller family size, with type 2 diabetes, and the presence of comorbidities were significant determinants for using paper-based methods to share SMBG results. The majority of the physicians (196/203, 96.6\%) constantly encouraged their patients to share the results, and most of them perceived that SMBG results are adequate for optimizing insulin doses.

Empirical evidence from studies worldwide suggests frequent monitoring of blood glucose to be significantly associated with effective glycemic control; hence, regular monitoring and sharing are highly recommended by the consensus [16-19]. Many international studies point towards a higher prevalence of daily blood glucose monitoring compared to sharing the results. For example, a nationwide Norwegian survey reported $70 \%$ of the patients practicing SMBG and less than $50 \%$ performing daily monitoring [20]. Another research from the United States noted $86 \%$ of insulin-users practice SMBG [21], while a regional study from Oman demonstrated a lower rate of $36 \%$; nevertheless, all of them showed a lesser prevalence of results-sharing with physicians [22]. On the contrary, compared to these studies, our results reflect the higher prevalence of monitoring practices; however, sharing SMBG results with physicians was considered optimal.

Monitoring and sharing are two interlinked practices of diabetes self-management. Monitoring helps patients track their glycemic levels daily, plan nutritional and activity routines, and improve their quality of life, whereas sharing helps physicians optimize insulin doses. Physician's motivation, in addition to diabetes self-management training and education programs, support the importance of monitoring and sharing practices. Our results showed that $93.6 \%(190 / 203)$ of the patients were encouraged by the physicians to monitor their glycemic status regularly, and $96.6 \%$ (196/203) were motivated to share the results. The encouraging attitude of the physicians reflected the high rate of monitoring; however, it did not effectively impact the rate of sharing. Of the 79\% (117/147) who shared the SMBG results, $64 \%(75 / 117)$ shared once every month or more, and $21 \%$ (25/117) shared daily.

Further analysis showed an increased frequency of sharing to be associated with type 2 diabetes and being a woman. Although the presence of other comorbidities was not associated with increased sharing, patients in the "no comorbidity" group shared more often daily and weekly. Other variables like uncontrolled diabetes or longer duration of diabetes also did not influence sharing frequency. A similar regional study from Western Saudi Arabia demonstrated a prevalence rate of $70 \%$ for measuring SMBG, with only $22 \%$ sharing the results with their physicians [23]. Our results showed higher rates of compliance when compared to the other regional literature. These are some important findings of our research which, if further investigated, might shed light on the causal reasons for frequent sharing that can be henceforth applied to augment effective diabetes management.

Furthermore, this study noted a slight preponderance towards the use of paper-based methods for sharing the results. However, the characteristics defining the method of use were unambiguous. Patients with higher age and those with lesser education preferred paper-based methods to digital devices. The other determinants like being married and the presence of comorbidities are also associated with age. One of the main reasons for the preponderance of paper-based methods could be related to the ease and comfort in recording the results right away. Since the patients are provided with a glucometer kit and notebook, many patients preferred saving the results in the notebook instantaneously compared to laptops or smartphones.

In the era of a digital revolution, the use of smartphones and digital devices is ubiquitous. One might expect a high dependency on smartphone applications for health-related information-sharing between patients and physicians. Our study has observed a transitional trend in the method of sharing, where the younger and more educated subjects preferred digital devices. Previous research has shown that uptake and sustained use of digital devices and applications for monitoring health depends on a number of factors like literacy, age, cognitive abilities, type and features of applications, and complexity of use [24]. Wildenbos et al [25] demonstrated poor usability and feasibility in using digital applications for health monitoring among older adults. Besides, complications in operations have largely contributed to aiding the discontinued use of digital applications for health benefits [26]. The findings from these studies establish the evidence in favor of predominant digital nonuse among senior people and the digitalization of younger patients, demonstrating consistency with our results. Identifying an emerging shift towards the use of digital technology in health care and contemplating the barriers of its application demonstrates the need to revise and reframe the structure of the standard diabetes education programs. Patient education programs could include training sessions demonstrating the use of digital devices and their applications in diabetes management.

Another key finding of the study is the adequacy of the shared blood glucose measurements in adjusting and customizing insulin doses. Almost 93\% (188/203) of the physicians perceived shared results were adequate for optimizing the insulin dose. This is a major clinical use of SMBG. A recent review based on evidence from 26 studies found SMBG to be highly beneficial in titrating insulin doses. It has the potential to influence the physicians' decision-making [27] as well as patients. Furthermore, some trials have demonstrated structured diabetes control programs achieving targeted glycemic control by using daily blood glucose monitoring results as a basis to 
self-adjust insulin dose in poorly or uncontrolled type 2 diabetes patients [28].

Finally, another interesting finding showed that those who used digital devices shared results three times more often than those who used paper methods. One of the reasons for using digital devices could be a relatively simpler and quicker process. Moreover, although not significant, the number of patients with uncontrolled diabetes in the device-using group was lesser than those in the paper-based group. In addition, the presence of comorbidities was significantly lesser in the device-using group. However, the role of confounders like age cannot be ruled out. Hence, digital devices can be considered as one of the facilitators of good sharing practices. Moreover, measurements from the digital devices can be synced, and the data can be stored in other devices for future reference. An Australian mobile health pilot program for diabetes control demonstrated digital device use and subsequent digital training to impact patients' self-management of diabetes substantially [29]. With this additional evidence, we highly recommend prioritizing digital literacy in diabetes self-management training and education programs.

However, the study does contain certain limitations. Limited generalizability is one of the study's major limitations since the research was conducted at a single tertiary care government referral center. The smaller sample size is also a potential limitation.

\section{Conclusions}

To our knowledge, this is the first study reporting the methods and determinants of the sharing practices of SMBG among insulin users in Saudi Arabia. The findings have good research and clinical implications. Future research exploring individual factors for patient preferences and monitoring adherence and detailed analyses of SMBG barriers are highly recommended. Furthermore, determinants, barriers, and facilitators of sharing and the effect of sharing on the disease status must be explored to understand the effective role of sharing SMBG results fully. However, this study provides resourceful literature and highlights the essentials of SMBG results sharing practices while recognizing the importance of the types of methods preferred that can substantially increase good practices. With diabetes beginning to affect more and more younger people, and owing to the widespread use of smartphones and other digital devices, digitalization can be considered one of the methods to increase diabetes monitoring. Numerous health applications in smartphones have been developed to assist in maintaining physical fitness, general health, and specific disease control like obesity and diabetes. Smartphone applications related to diabetes control and built-in glucometer software technologies enable users to keep track of their blood glucose and assist in optimum diabetes management through lifestyle modification strategies. Hence diabetes education and self-management programs can consider redesigning the curriculum to include training in the use of smartphone applications in diabetes self-management.

\section{Acknowledgments}

The authors thank Muneera Mohammed Faloudah, Family Medicine Consultant.

Ghaida Ali Alshehri, Amira Mohammed Aldakhilallah, Renad Mohammed Alhaqbani, Felwah Saleh Al Saawi, and Lojain Abdullah Azizalrahman for their efforts in collecting data. The authors are grateful to the Deanship of Scientific Research, King Saud University, for funding provided through the Vice Deanship of Scientific Research Chairs.

\section{Authors' Contributions}

AJ, ST, MB, and NS contributed to the conception and design of the study and data interpretation. WB, SA, AA, MA, NA, and SO participated in data acquisition and statistical analysis. ST assisted in the analysis and drafted the manuscript. All authors read and approved the final manuscript.

\section{Conflicts of Interest}

None declared.

\section{References}

1. Stehouwer CD. Microvascular Dysfunction and Hyperglycemia: A Vicious Cycle With Widespread Consequences. Diabetes 2018 Aug 22;67(9):1729-1741. [doi: 10.2337/dbi17-0044]

2. Emanuelsson F, Marott S, Tybjærg-Hansen A, Nordestgaard BG, Benn M. Impact of Glucose Level on Micro- and Macrovascular Disease in the General Population: A Mendelian Randomization Study. Diabetes Care 2020 Apr 13;43(4):894-902. [doi: 10.2337/dc19-1850] [Medline: $\underline{\text { 32054721] }}$

3. Smith-Palmer J, Brändle M, Trevisan R, Orsini Federici M, Liabat S, Valentine W. Assessment of the association between glycemic variability and diabetes-related complications in type 1 and type 2 diabetes. Diabetes Research and Clinical Practice 2014 Sep;105(3):273-284. [doi: 10.1016/j.diabres.2014.06.007]

4. Shrivastava SR, Shrivastava PS, Ramasamy J. Role of self-care in management of diabetes mellitus. J Diabetes Metab Disord 2013 Mar 05;12(1):14-18 [FREE Full text] [doi: 10.1186/2251-6581-12-14] [Medline: 23497559]

5. American Diabetes Association. Standards of Medical Care in Diabetes--2012. Diabetes Care 2011 Dec 20;35(Supplement_1):S11-S63. [doi: 10.2337/dc12-s011] 
6. Silver B, Ramaiya K, Andrew SB, Fredrick O, Bajaj S, Kalra S, et al. EADSG Guidelines: Insulin Therapy in Diabetes. Diabetes Ther 2018 Mar 5;9(2):449-492. [doi: 10.1007/s13300-018-0384-6]

7. Deshmukh V, Deshmukh C. Achieving good glycaemic control-effective use of self monitoring of blood glucose (SMBG). J Indian Med Assoc 2012 Mar;110(3):161-163. [Medline: 23029947]

8. Farmer A, Wade A, Goyder E, Yudkin P, French D, Craven A, et al. Impact of self monitoring of blood glucose in the management of patients with non-insulin treated diabetes: open parallel group randomised trial. BMJ 2007 Jun 25;335(7611):132. [doi: 10.1136/bmj.39247.447431.be]

9. García de la Torre N, Durán A, Del Valle L, Fuentes M, Barca I, Martín P, et al. Early management of type 2 diabetes based on a SMBG strategy: the way to diabetes regression--the St Carlos study : a 3-year, prospective, randomized, clinic-based, interventional study with parallel groups. Acta Diabetol 2013 Aug 27;50(4):607-614. [doi: 10.1007/s00592-013-0467-9] [Medline: 23532298]

10. Harashima S, Fukushima T, Sasaki M, Nishi Y, Fujimoto S, Ogura M, et al. Self-monitoring of blood glucose (SMBG) improves glycaemic control in oral hypoglycaemic agent (OHA)-treated type 2 diabetes (SMBG-OHA study). Diabetes Metab Res Rev 2013 Jan 08;29(1):77-84. [doi: 10.1002/dmrr.2363]

11. Mensing C, Boucher J, Cypress M, Weinger K, Mulcahy K, Barta P, et al. National Standards for Diabetes Self-Management Education. Diabetes Care 2006 Dec 27;30(Supplement 1):S96-S103. [doi: 10.2337/dc07-s096]

12. Inzucchi S, Bergenstal R, Buse J. Management of Hyperglycemia in Type 2 Diabetes, 2015: A Patient-Centered Approach. Update to a Position Statement of the American Diabetes Association and the European Association for the Study of Diabetes. Diabetes Care 2015; a patient-centered approach:140-149. [doi: 10.2337/dc15-0812]

13. Self-Monitoring of Blood Glucose in Non-Insulin Treated Type 2 Diabetes. URL: https://www.idf.org/e-library/guidelines/ 85-self-monitoring-of-blood-glucose-in-non-insulin-treated-type-2-diabetes.html [accessed 2021-02-26]

14. Ruiz Gracia T, García de la Torre Lobo N, Durán Rodríguez Hervada A, Calle Pascual AL. Structured SMBG in early management of T2DM: Contributions from the St Carlos study. World J Diabetes 2014 Aug 15;5(4):471-481 [FREE Full text] [doi: 10.4239/wjd.v5.i4.471] [Medline: 25126393]

15. Ong WM, Chua SS, Ng CJ. Barriers and facilitators to self-monitoring of blood glucose in people with type 2 diabetes using insulin: a qualitative study. Patient Prefer Adherence 2014;8:237-246 [FREE Full text] [doi: 10.2147/PPA.S57567] [Medline: 24627628]

16. Miller KM, Beck RW, Bergenstal RM, Goland RS, Haller MJ, McGill JB, et al. Evidence of a strong association between frequency of self-monitoring of blood glucose and hemoglobin A1c levels in T1D exchange clinic registry participants. Diabetes Care 2013 Jul;36(7):2009-2014 [FREE Full text] [doi: 10.2337/dc12-1770] [Medline: 23378621]

17. Ziegler R, Heidtmann B, Hilgard D, Hofer S, Rosenbauer J, Holl R, DPV-Wiss-Initiative. Frequency of SMBG correlates with HbA1c and acute complications in children and adolescents with type 1 diabetes. Pediatr Diabetes 2011 Feb;12(1):11-17. [doi: 10.1111/j.1399-5448.2010.00650.x] [Medline: 20337978]

18. Machry RV, Rados DV, Gregório GR, Rodrigues TC. Self-monitoring blood glucose improves glycemic control in type 2 diabetes without intensive treatment: A systematic review and meta-analysis. Diabetes Res Clin Pract 2018 Aug;142:173-187. [doi: 10.1016/j.diabres.2018.05.037] [Medline: 29857093]

19. Sieber J, Flacke F, Link M, Haug C, Freckmann G. Improved Glycemic Control in a Patient Group Performing 7-Point Profile Self-Monitoring of Blood Glucose and Intensive Data Documentation: An Open-Label, Multicenter, Observational Study. Diabetes Ther 2017 Oct;8(5):1079-1085 [FREE Full text] [doi: 10.1007/s13300-017-0306-z] [Medline: 28913822]

20. Kjome RL, Granas AG, Nerhus K, Roraas TH, Sandberg S. The Prevalence of Self-Monitoring of Blood Glucose and Costs of Glucometer Strips in a Nationwide Cohort. Diabetes Technology and Therapeutics 2010 Sep;12(9):701-705. [doi: 10.1089/dia.2010.0056]

21. Centers for Disease Control and Prevention (CDC), 1997-2006. Self-monitoring of blood glucose among adults with diabetes_United States, 1997-2006. MMWR Morb Mortal Wkly Rep 2007;56:1137.

22. Nazmi A, Hadithi D, Khan S. Self monitoring of blood glucose level among diabetic patients in Muscat, Oman: A pilot study. Saudi J Health Sci 2013;2(1):54. [doi: 10.4103/2278-0521.112632]

23. Mansouri D, Alawi H, Barasyn K, Bnnounh M, Haddad N, Al-Hafdey D, et al. Self-monitoring of blood glucose among diabetic patients attending Al-Eskan Primary Health Care Center in Makkah Al-Mukarramah city. Int J Med Sci Public Health 2015;4(4):527. [doi: 10.5455/ijmsph.2015.25012015109]

24. Gao C, Zhou L, Liu Z, Wang H, Bowers B. Mobile application for diabetes self-management in China: Do they fit for older adults? Int J Med Inform 2017 Dec;101:68-74 [FREE Full text] [doi: 10.1016/j.ijmedinf.2017.02.005] [Medline: 28347449]

25. Wildenbos GA, Peute L, Jaspers M. Aging barriers influencing mobile health usability for older adults: A literature based framework (MOLD-US). Int J Med Inform 2018 Jun;114:66-75. [doi: 10.1016/j.ijmedinf.2018.03.012] [Medline: 29673606]

26. Zhang Y, Li X, Luo S, Liu C, Xie Y, Guo J, et al. Use, Perspectives, and Attitudes Regarding Diabetes Management Mobile Apps Among Diabetes Patients and Diabetologists in China: National Web-Based Survey. JMIR Mhealth Uhealth 2019 Feb 08;7(2):e12658 [FREE Full text] [doi: 10.2196/12658] [Medline: $\underline{\text { 30735147] }}$

27. Silva DDR, Bosco AA. An educational program for insulin self-adjustment associated with structured self-monitoring of blood glucose significantly improves glycemic control in patients with type 2 diabetes mellitus after 12 weeks: a randomized, controlled pilot study. Diabetol Metab Syndr 2015 Jan 15;7(1):1-9. [doi: 10.1186/1758-5996-7-2] 
28. Frías-Ordoñez JS, Pérez-Gualdrón CE. Self-monitoring of blood glucose as control tool in the different management contexts for Type 2 Diabetes Mellitus. What is its current role in non-insulin users? Rev Fac Med 2019 Jul 01;67(3):293-303. [doi: 10.15446/revfacmed.v67n3.69687]

29. Park S, Burford S, Nolan C, Hanlen L. The Role of Digital Engagement in the Self-Management of Type 2 Diabetes. Health Commun 2016 Dec 28;31(12):1557-1565. [doi: 10.1080/10410236.2015.1089468] [Medline: 27124817]

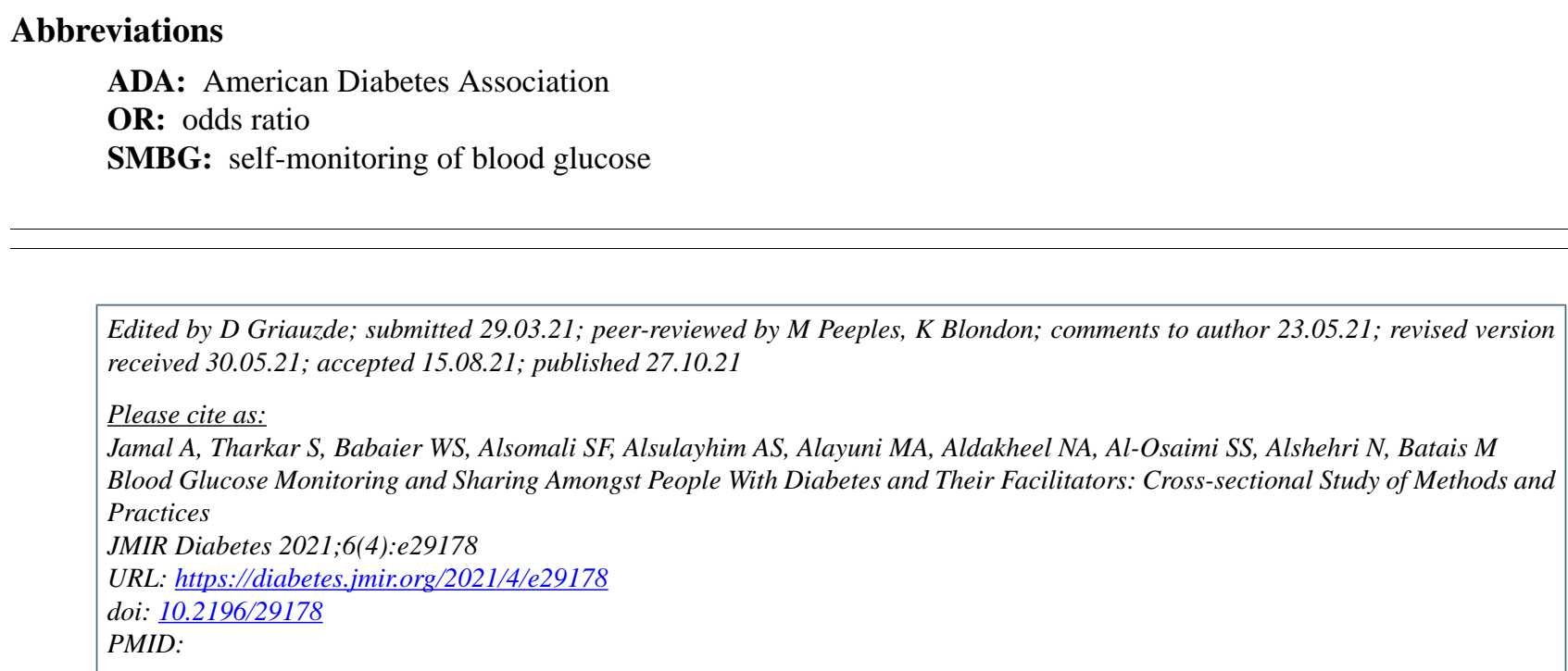

(C)Amr Jamal, Shabana Tharkar, Weam Saleh Babaier, Shrooq Faisal Alsomali, Allulu Saad Alsulayhim, Monera Abdulkareem Alayuni, Nada Abdulaziz Aldakheel, Safa Sultan Al-Osaimi, Norah Alshehri, Mohammed Batais. Originally published in JMIR Diabetes (https://diabetes.jmir.org), 27.10.2021. This is an open-access article distributed under the terms of the Creative Commons Attribution License (https://creativecommons.org/licenses/by/4.0/), which permits unrestricted use, distribution, and reproduction in any medium, provided the original work, first published in JMIR Diabetes, is properly cited. The complete bibliographic information, a link to the original publication on https://diabetes.jmir.org/, as well as this copyright and license information must be included. 